\title{
Yield Curve and Momentum Effects in Monthly U.S. Equity Returns: Some Nonparametric Evidence
}

\author{
Somya Tyagi ${ }^{1}$ \\ Sikandar Siddiqui ${ }^{2}$ (iD \\ ${ }^{2}$ Frankfurt School Financial Services GmbH, Frankfurt, Germany \\ SCDM Germany GmbH, Frankfurt, Germany
}

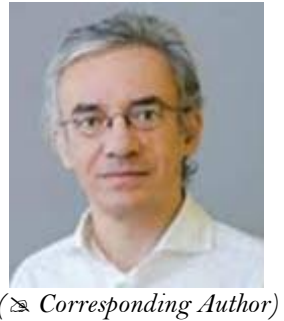

\begin{abstract}
In this paper, two largely familiar stock market anomalies - the yield curve and the momentum effects - are re-examined for the S\&P 500 index by using nonparametric regression. The results essentially confirm the existence of both of these phenomena, but also indicate that the stochastic linkages between the explanatory variables and future index returns are nonlinear and mutually dependent. It hence turns out that the greater flexibility offered by nonparametric regression enables the detection and characterisation of some features of the underlying relationship that would have been gone unnoticed under the linearity and additivity assumptions underlying simpler regression approaches.
\end{abstract}

Keywords: Stock market, Yield curve effect, Momentum, Nonparametric regression.

JEL Classifications: G10, C58.

Citation | Somya Tyagi; Sikandar Siddiqui (2017). Yield Curve and Momentum Effects in Monthly U.S. Equity Returns: Some Nonparametric Evidence. Asian Journal of Economics and Empirical Research, 4(2): 61-67.

History:

Received: 20 September 2017

Revised: 5 October 2017

Accepted: 14 October 2017

Published: 18 October 2017

Licensed: This work is licensed under a Creative Commons Attribution 3.0 License $(\mathrm{cc})$

Publisher:Asian Online Journal Publishing Group
Contribution/Acknowledgement: Both authors contributed to the conception and design of the study.

Funding: This study received no specific financial support.

Competing Interests: The authors declare that they have no conflict of interests.

Transparency: The authors confirm that the manuscript is an honest, accurate, and transparent account of the study was reported; that no vital (n) study have been omitted; and study as planned have been explained.

Ethical: This study follows all ethical practices during writing.

\section{Contents}

1. Introduction 62

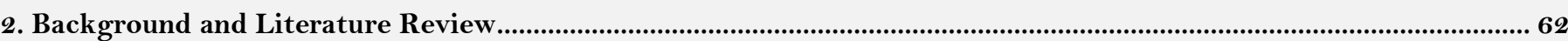

3. Data . 63

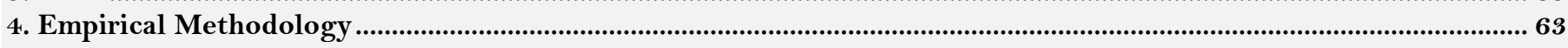

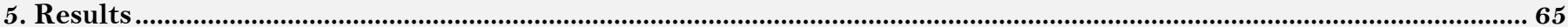

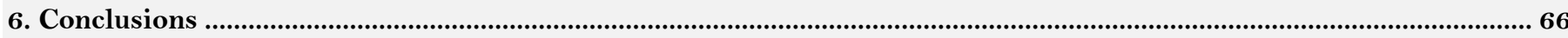

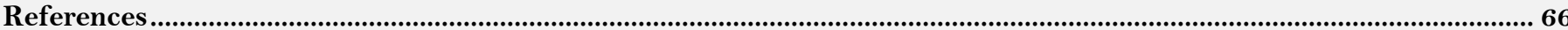




\section{Introduction}

In its "weak", i.e. least restrictive form, the capital market efficiency hypothesis states that at any given time the market price of an asset reflects all the relevant information contained in historical data (see e.g., Fama (1970)). This once popular assertion has, in recent years, repeatedly been challenged by a variety of research outcomes. From the application of statistical forecasting models to historical time series of asset prices, mostly from the equity markets, a considerable number of potential leading indicators have emerged to which some prognostic potential for price movements has been ascribed. Examples include momentum, i.e. the relative change in the observed asset price over one or more a pre-defined past time windows (see, e.g., the pioneering work by Jegadeesh and Titman (1993) seasonal indicators (Gultekin and Gultekin, 1983) measures of intrinsic value like, e.g., price/book or price/earnings ratios (Basu, 1977; Rosenberg et al., 1985) as well as macroeconomic indicators like interest rates (Chen et al., 1986) to name but a few.

It seems that to date, the method of choice for testing the validity of the weak-form efficient market hypothesis, or identifying departures from it, has often been linear regression. This way of proceeding is based on the implicit assumption that the deterministic part of the underlying statistical relationship between the dependent variable (here: the asset return over the forecast horizon) and the supposed leading indicators is adequately represented mathematically by a linear, additive function. Given the large variety of non-linear or mutually interlinked patterns according to which two or more factors of influence could jointly impact a random variable of interest, this premise might easily be looked upon as an undue simplification. If adopted in an unchallenged manner, it could thus lead users to miss out on important features of the unknown, actual data-generating process.

A possible solution attempt to this problem would be to replace the linear function used for the conditional mean of the dependent variable by functional forms that allow for a greater degree of flexibility in the representation of (possibly) complex relationships. Among the most important advances in this field are the threshold time series models pioneered by Tong (1983) where one or more threshold values of an explanatory variable are used to define intervals among which the values taken by the regression coefficients are allowed to differ. The same applies to the Markov Switching Model by Hamilton (1989) which allows for two or more régimes between which the behaviour of the time series investigated differs systematically, and in which transitions from one régime to another are controlled by a latent state variable of which the current level is a function of its most recent past value.

The above approaches, however, are built on the premise that the functional relationship between the variables under investigation is known a priori up to a finite number of parameters, which might still be regarded as questionable. This makes the case in favour of considering nonparametric regression, in which the conditional mean function is not determined a priori but derived entirely from the data, as an alternative. On this background, the purpose of this paper is to investigate whether, and how, applying the nonparametric method of local least squares regression can assist in characterising two frequently perceived stock market anomalies, i.e. the momentum and the yield curve effects, using the example of the S\&P 500 equity market index.

The remainder of the paper is organised as follows: Section 2 provides some additional background and a (necessarily selective) overview of the relevant literature. A brief description of the data in use is provided in Section 3, whereas Section 4 focuses on the empirical methodology employed. The estimation results obtained are summarised and discussed in Section 5. The paper ends with a summary of the main conclusions and suggestions for future research (Section 6).

\section{Background and Literature Review}

Among the market anomalies that have, so far, attracted the attention of both academics and practitioners, the momentum effect is arguably among the most thoroughly investigated. One of the earliest wide-ranging investigations of this topic has been provided by Jegadeesh and Titman (1993) who found that an equity investment strategy that combines long positions in the best-performing U.S. stocks from the past 3-12 months with short positions in the worst performing ones during the same formation period, would, on average, bring about a monthly rate of return of around 1\% during the subsequent 1 to 3 months. Following up on this topic at a later stage, the authors (Jegadeesh and Titman, 2001) reach the conclusion that such momentum returns continued to prevail during the 1990 s (and find that equity returns have a tendency to revert over longer time horizons). A considerable number of other studies have essentially confirmed the prevalence of momentum effects in several segments of the international equity markets; examples include Rouwenhorst (1998;1999) for Europe and several emerging markets, as well as Chui et al. (2003) for a number of Asian countries. For stock market indexes and exchange trade funds, rather than individual shares, significant momentum effects have been reported, inter alia, by Asness et al. (1996); Richards (1997); Chan et al. (2000) and Tse (2015) among others.

A number of mutually complementary explanations for these phenomena exist. One of them is that news relevant to valuation spread gradually, rather than instantaneously, among market participants, and that different investors require different amounts of time to figure out what exactly a piece of newly arrived information actually implies for asset prices. This possibility is consistent with the hypothesis by Jegadeesh and Titman (2001) that investors initially tend to underreact to new information. Moreover, some investors might seek to learn by watching others whom they consider more sophisticated, or better informed, before rebalancing their own portfolios. This would be in line with the model by Hong and Stein (1999) according to which two investor groups - informed investors (who are equipped with a competitive advantage in obtaining and processing relevant information) and technical traders (who form expectations on future returns based on perceived patterns in past price movements) - exist. The delayed reaction of the second group to price movements caused by transactions by members of the first can cause asset prices to over- or undershoot their fundamentally justified values. The overreaction hypothesis also discussed in Jegadeesh and Titman (2001) also points in this direction. Moreover, if many investors tend to base their expectations of future asset returns at least partially on trends from the recent past, and trade accordingly, the subsequent price impacts of this behavioural pattern may generate consecutive, temporarily self-perpetuating "feedback loops" (Shiller, 2005). 
For quite some time, economists have also argued that the slope of the yield curve, i.e. the difference between long and short-term interest rates for credit products of a given quality class, is a promising candidate variable for a leading indicator of turning points in the business cycle. This presumption is supported by (at least) two mutually complementary theoretical considerations:

(1) Commercial banks typically engage in maturity transformation, i.e. they refinance longer-term lending transactions through revolving short-term borrowings, and hence tend to gain from a steeper yield curve (see, e.g., Alessandrini and Nelson (2012)). By boosting a bank's profit margins, such a constellation tends to encourage commercial banks to lend more freely to nonbanks, with the likely impact of stimulating aggregate demand and output - at least if the economy does not yet operate at full capacity utilisation. A flat or downward sloping yield curve, in contrast, tends to depress bank profit margins, choke new lending, and slow down the growth of aggregate demand.

(2) Central banks serve as lenders of last resort to the domestic commercial banking sector. By unilaterally setting the refinancing rates at which it lends central bank money to commercial banks, the central bank of a currency area can strongly impact (albeit not perfectly control) short-term rates prevailing on the interbank market for central bank balances. Towards the long end of the yield curve, interest rates, while being far from unaffected by central bank actions, are commonly believed to be more strongly influenced by market expectations on future short-term rates and inflation, as explained in Estrella and Mishkin (1996). Hence, a flat or even downward-sloping yield curve is usually indicative of a restrictive central bank policy that aims at limiting money supply growth and reducing inflation, albeit at the cost of a (temporary) slowdown in economic activity. Conversely, an upward slope that appears outstandingly steep by historical standards often is a by-product of an expansionary monetary policy stance.

Meanwhile, several empirical findings have supported the above line of reasoning. Among the early examples for this are the works by Estrella and Hardouvelis (1991); Estrella and Mishkin (1996;1998) as well as Smets and Tsatsaronis (1997) more recent related contributions include papers by Stock and Watson (2003); Ang and Piazzesi (2003) and Diebold et al. (2006).

If market participants do indeed react gradually, and at different speeds, to the arrival of new information, the suggestion by Siegel (1998) that a reliable predictor of turning points in the business cycle would also be a useful tool in timing the stock market would hence encourage to use the slope of the yield curve as a lead indicator for the equity market, too. By now, a considerable body of literature has accumulated that essentially confirms this perception. Examples of related studies include Campbell (1987); Fama and French (1989); Schwert (1990); Campbell and Ammer (1993) and Boudoukh et al. (1997) as well as Resnick and Shoesmith (2002).

\section{Data}

In the context of this paper, the one-month lagged slope of the yield curve (referred to by the abbreviation $\mathrm{SLOPE}_{-1}$ ) is measured by the difference between the seasonally unadjusted end-of-month values of the 10-Year Treasury Constant Maturity Rate and the Effective Federal Funds Rate, as published Federal Reserve Bank of St. Louis ${ }^{1}$. For calculating the monthly rates of return on the S\&P 500 index $(\mathrm{R} 1 \mathrm{M})$ and the lagged momentum indicator $\mathrm{MOM}_{-1}$, the end-of-month index levels made available by Yahoo! Finance ${ }^{2}$ are used. In line with a common practice, the time horizon over which momentum indicator was calculated amounts to 12 months. The sampling period ranges from 1960 to 2015. Descriptive statistics of the variables in use are provided in Table 1 below.

Table-1. Descriptive Statistics of Variables in Use

\begin{tabular}{l|c|c|c}
\hline & R1 M & SLOPE-1 & MOM-1 \\
\hline Mean & 0.0053 & 0.0106 & 0.0638 \\
\hline Standard Deviation & 0.0428 & 0.0168 & 0.1573 \\
\hline Skewness & -0.6750 & -1.1364 & -0.9188 \\
\hline Excess Kurtosis & 2.5693 & 2.1463 & 1.3873 \\
\hline Minimum & -0.2454 & -0.0651 & -0.5934 \\
\hline $5 \%$ quantile & -0.0680 & -0.0207 & -0.2191 \\
\hline $10 \%$ quantile & -0.0483 & -0.0083 & -0.1489 \\
\hline $25 \%$ quantile & -0.0181 & 0.0017 & -0.0194 \\
\hline Median & 0.0090 & 0.0124 & 0.0927 \\
\hline $75 \%$ quantile & 0.0337 & 0.0226 & 0.1686 \\
\hline $90 \%$ quantile & 0.0528 & 0.0297 & 0.2372 \\
\hline $95 \%$ quantile & 0.0696 & 0.0328 & 0.2735 \\
\hline Maximum & 0.1510 & 0.0385 & 0.4249 \\
\hline \# observations & 671 & 671 & 671 \\
\hline
\end{tabular}

\section{Empirical Methodology}

\subsection{Problem Formulation and Objective}

In the following, $y_{t}$ denotes the rate of return on the S\&P 500 stock market index between the last trading days of two subsequent months $t$ and $t-1$. Moreover, $x_{1, t-1}$ stands for the lagged 12-month rate of return on the same index, and $x_{2, t-1}$ the difference between the par yield on ten-year U.S. Treasury bonds and the federal funds rate. The last month for which an observation of $y$ is available in the dataset is denoted by $T$. The objective pursued here is to estimate the conditional mean function of $y_{t}$ without imposing any overly restrictive preconditions (such as linearity and additivity) on the form of the statistical relationship between $y_{t}$ and the two explanatory variables $x_{1, t-1}$, and $x_{2, t-1}$. It is assumed that the regression equation by which this unknown relationship can be expressed reads

\footnotetext{
' See https://research.stlouisfed.org/fred2

${ }^{2}$ See http://finance.yahoo.com/
} 


$$
y_{t}=g\left(x_{1, t-1}, x_{2, t-1}\right)+u_{t}
$$

where $u_{t}$ is the time-specific realization of a scalar random variable with mean zero that is independent of $x_{t}$ and $x_{2}$.

\subsection{Estimation Method}

As shown by Hastie and Tibshirani (1993) one way of estimating an unknown function like $g($.$) above is to use$ a pre-defined function of both the explanatory variables and a set of unknown parameters $\alpha, \beta_{1}$, and $\beta_{2}$ in its place, all of which are allowed to vary with the specific values taken by the explanatory variables. In our application, this would imply approximating (1) by

$$
y_{t}=\alpha\left(x_{1, t-1}, x_{2, t-1}\right)+x_{1, t-1} \cdot \beta_{1}\left(x_{1, t-1}, x_{2, t-1}\right)+x_{2, t-1} \cdot \beta_{2}\left(x_{1, t-1}, x_{2, t-1}\right)+\varepsilon_{t}
$$

Here, the scalar $\varepsilon_{\mathrm{t}}$ represents the cumulative impact of the random error $u_{t}$ and any possible approximation error incurred when replacing $g(\cdot)$ by the corresponding term in (2). Then, for any combination $\left\{x_{1}^{*}, x_{2}^{*}\right\}$ of values lying inside the empirically observed range of $x_{1, \mathrm{t}-1}$ and $x_{2, \mathrm{t}-1}$, a set $\hat{\alpha}\left(x_{1}^{*}, x_{2}^{*}\right), \hat{\beta}_{1}\left(x_{1}^{*}, x_{2}^{*}\right)$, and $\hat{\beta}_{2}\left(x_{1}^{*}, x_{2}^{*}\right)$ of related estimates can be calculated my minimizing the criterion function

$$
\Xi\left(\tilde{\alpha}, \tilde{\beta}_{1}, \tilde{\beta}_{2}, \cdot\right)=\sum_{t=2}^{T}\left(y_{t}-\tilde{\alpha}-\tilde{\beta}_{1} \cdot x_{1, t-1}-\tilde{\beta}_{2} \cdot x_{2, t-1}\right)^{2} \cdot K_{h_{1}}\left(x_{1, t-1}, \cdot\right) \cdot K_{h_{2}}\left(x_{2, t-1}, \cdot\right)
$$

with respect to the trial parameters $\tilde{\alpha}, \tilde{\beta}_{1}$, and $\tilde{\beta}_{2}$.

In the above equation, the expression $K_{h_{i}}\left(x_{i, t-1}, \cdot\right), i=1,2$, termed a kernel function, is a weighting function of which the value shrinks as the distance between $x_{i,-t}$ and $x_{i}{ }^{*}$ increases. In this application, the kernel function is set to

$$
K_{h_{i}}\left(x_{i, t-1}, \cdot\right)=\frac{1}{h_{i}} \phi\left(\frac{x_{i, t-1}-x_{i}^{*}}{h_{i}}\right)
$$

where $\phi(\cdot)$ stands for the Standard Normal density. (Several other symmetric univariate probability density functions could also have been used in its place without substantially affecting the accuracy of the estimates; see, e.g., Härdle (1990) section 4.5). The scalar quantities $h_{1}$ and $h_{2}$ are bandwidth parameters which jointly determine how quickly the weight placed on an individual observation $\left\{y_{t}, x_{1, t-1}, x_{2, t-1}\right\}$ in (3) declines as the distance between $x_{i}^{*}$ and $x_{i, t-1}($ with $i=1,2)$ grows.

\subsection{Bandwidth Choice}

For given values of the bandwidth parameters $h_{l}$ and $h_{2},(3)$ is a standard, analytically tractable, weighted-least squares problem. Selecting appropriate values for $h_{1}$ and $h_{2}$ is of crucial importance: If, on one hand, the chosen bandwidth parameters are "too small", the resulting estimates tend to "fit the noise", i.e. to be too sensitive to the specific realizations of the random influences present in the data, to possess excessive variance, and to be poorly generalizable. On the other hand, choosing them to be "too large" will cause important features in the unknown, true function $g(\cdot)$ to remain unnoticed. What further complicates the issue is that using a globally constant set of bandwidths might simultaneously lead to an undesirably large bias of the fitted function in areas densely populated with data points, and to an overly erratic behaviour in areas where only few observations are located. In line with $\mathrm{Li}$ and Racine (2007) section 14.8, the solution to this problem advocated here is to relate the bandwidth $h_{i}$ to $x_{i}^{*}(i$ $=1,2)$ by setting

$$
h_{i}\left(x_{i}^{*}\right)=d\left(k_{i}, x_{i}^{*}\right)
$$

where $d\left(k_{i}, x_{i}^{*}\right)$ is the absolute difference between $x_{i}^{*}$ and its $k_{-}$-th closest neighbouring observation among the $x_{i t}$ for $\mathrm{t}=1, \ldots, T-1$. By allowing different values of $k_{i}$ for $i=1$ and 2 , we account for the possibility that the profile of the function $g(\cdot)$ to be estimated might be (close to) linear in one dimension but considerably more variable in the other. For non-integer values of $k_{i}$, the corresponding value of $d\left(k_{i}, x_{i}^{*}\right)$ can be obtained by linear interpolation between the two adjacent whole numbers.

Then, a possible solution to the trade-off between the goals of mitigating the bias inherent in the approximate nature of (2) and avoiding to "fit the noise" is to follow Härdle (1990) (section 5.1.1.) in choosing the "optimal" combination $\left\{k_{1}^{(o p t)}, k_{2}^{(o p t)}\right\}$ of bandwidth parameters by minimizing the cross validation criterion

$$
C V_{t}=\sum_{t=2}^{T}\left(y_{t}-\hat{\alpha}_{\neg t}\left(x_{1, t-1}, x_{2, t-1}\right)+x_{1, t-1} \cdot \hat{\beta}_{1, \neg t}\left(x_{1, t-1}, x_{2, t-1}\right)+x_{2, t-1} \cdot \hat{\beta}_{2, \neg t}\left(x_{1, t-1}, x_{2, t-1}\right)\right)^{2}
$$

simultaneously with respect to $k_{l}$ and $k_{2}$. In Equation (5), the symbols $\hat{\alpha}_{-t}, \hat{\beta}_{1,-t}$, and $\hat{\beta}_{2,-t}$ denote "leave-one-out" estimates of the related parameters, i.e. estimates calculated along the same lines as $\hat{\alpha}\left(x_{1, t-1}, x_{2, t-1}\right), \hat{\beta}_{1}\left(x_{1, t-1}, x_{2, t-1}\right)$, and $\hat{\beta}_{2}\left(x_{1, t-1}, x_{2, t-1}\right)$ (see Equation (3)) but by deliberately leaving out the data point $\left\{y_{t}, x_{1, t-1}, x_{2, t-1}\right\}$.

Minimizing (5) constitutes a two-dimensional optimisation problem with possibly more than one local minimum. From the number of optimisation heuristics that can be used to tackle such a problem (see, e.g., the survey by Gilli and Winker (2009) the Differential Evolution algorithm by Storn and Price (1997) has been chosen here. Readers interested in the details of its implementation are referred to Gilli and Schumann (2010).

\subsection{Estimation of Pointwise Confidence Intervals}

Following a recommendation by Racine (2008), pointwise confidence intervals for both the parameter estimates and the fitted values of $y$ are estimated by bootstrapping (see Efron (1979)). In its simplest variant, which has been 
employed here, this involves creating a large number $B$ (here: 1,000) of pseudo-samples, each having the same number of observations as the original dataset, by randomly sampling from the original sample with replacement. Then, the quantities of interest are re-estimated for each of these pseudo-samples separately, and the estimated confidence bands for these quantities are inferred from the empirical quantiles of the $B$ resulting estimates. In what follows, an estimate is said to be significantly above (below) zero if zero lies outside the corresponding 95\% confidence interval.

\section{Results}

Figure 1 displays a two-dimensional surface plot of the estimated mean one-month rate of return on the S\&P $500(\mathrm{R} 1 \mathrm{M})$ index as a function of both the one-month lagged realisations of the slope of the yield curve (SLOPE $\left.\mathrm{S}_{-1}\right)$ and the 12-month momentum indicator $\mathrm{MOM}_{-1}$, together with the related $95 \%$ confidence interval. Figure 2 reproduces the same relationship in the form of a two-dimensional altitude chart, in which those areas where the estimated mean one-month rate of return on the $\mathrm{S} \& \mathrm{P} 500(\mathrm{R} 1 \mathrm{M})$ significantly differs from zero are highlighted in grey to facilitate their detection, and the individual data points are shown as black dots.

The results thus summarized support the hypothesis that a statistical relationship between the S\&P 500 index returns and both explanatory variables in use does indeed exist. However, they also convey the impression that $\mathrm{SLOPE}_{-1}$ and $\mathrm{MOM}_{-1}$ interact in a way that is neither linear nor additive when determining the conditional expectation of R1M. This is also underscored by the optimized values of $k_{l}$ and $k_{2}$ (see Equation 5), which stand at 413 and 546, respectively, and thus are not only finite but lie well below the sample size.

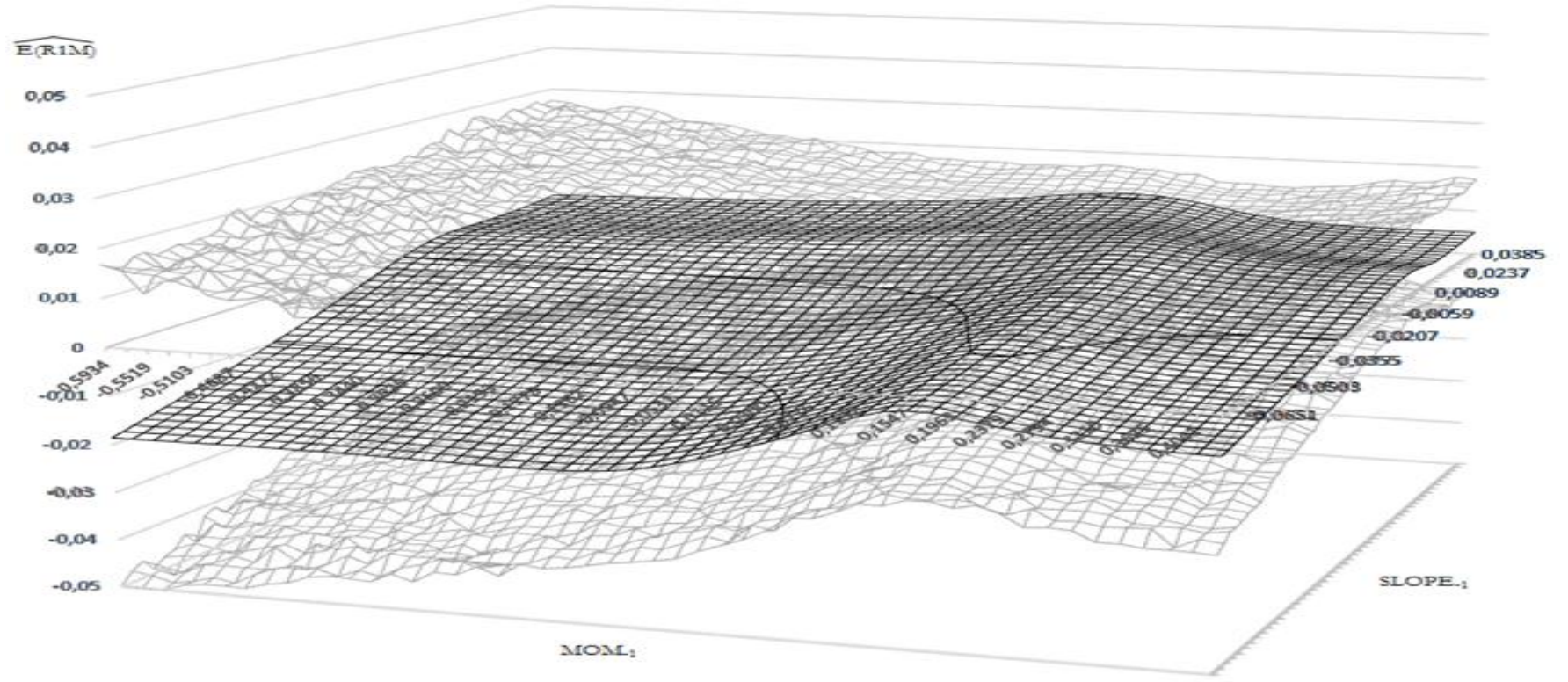

Figure-1. Regression Surface with 95\% Confidence Interval Upper and Lower Bounds

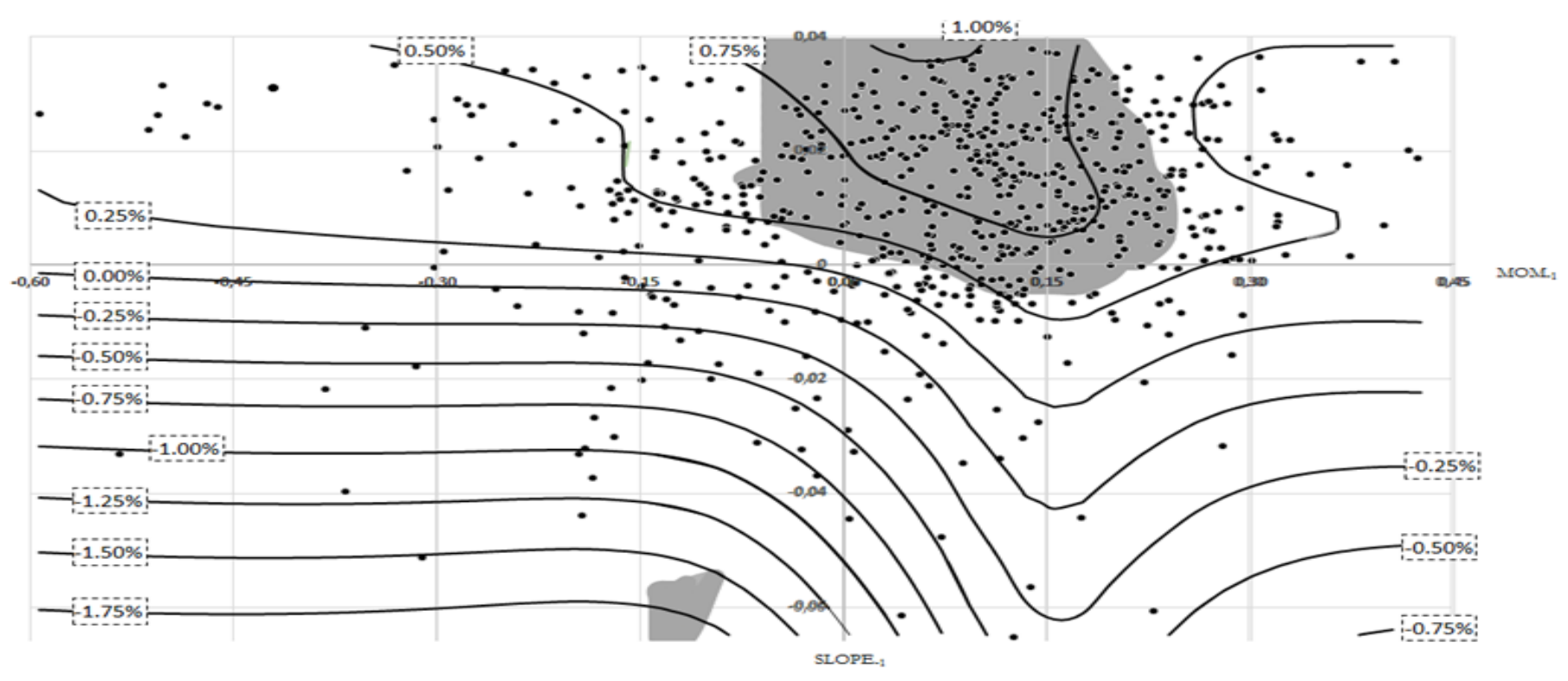

Figure-2. Regression Results as Altitude Chart

More specifically, a statistically significant momentum effect only appears to be present in situations where the slope of the yield curve is either positive or, at least, exceeds a threshold of (roughly) minus 40 basis points. For all values of $\mathrm{SLOPE}_{-1}$ below that boundary, the estimated lower limit of the $95 \%$ confidence interval lies below zero. In addition, it can be seen that for all values of SLOPE where a statistically significant momentum effect can be detected, the estimated relationship between the momentum indicator and the one-month ahead rate of return on the S\&P 500 appears neither linear nor even monotonic. Rather, there seems to be a threshold for MOM somewhere near between 0.05 and 0.15 (the exact value of which varies with SLOPE), up to which the higher values of $\mathrm{MOM}_{-1}$ tend to be associated with higher values of $\mathrm{R} 1 \mathrm{M}$ (as suggested by much of the earlier empirical literature), but above which this relationship flattens out or even becomes negative. Generally speaking, towards both ends of the momentum scale, the confidence intervals for the estimates widen substantially, thus indicating that in the sequel of unusually large jumps or drops in the index during the past 12 months, statistically 
meaningful inferences about the expected size and direction of future stock index movements are not possible. This can, at least in part, simply be attributed to the very limited number of data points in these regions of the data range.

Seen from the other angle, the findings obtained are also largely in line with earlier findings indicating a positive association between the slope of the yield curve and the magnitude of expected stock index returns. However, they also indicate that this relationship is not a "global" phenomenon, i.e. one that prevails with equal strength in all situations, but rather a "local" one that is most pronounced in terms of statistical significance in cases where the momentum indicator (again, roughly speaking) lies in a range from $-15 \%$ to $+25 \%$. For values of $\mathrm{MOM}_{-1}$ that lie outside this interval, again, a statistically significant linkage of the above type cannot be identified, most probably because near the boundaries of the plane spanned by the empirically observed ranges of SLOPE and MOM, observations are both too sparse and too widely scattered to allow any substantial conclusions.

In the above, the highest estimates of the mean one-month ahead S\&P 500 return are obtained for cases of a joint occurrence of a steep, positively sloped yield curve and a moderately positive momentum factor. This indicates that $\mathrm{SLOPE}_{-1}$ and $\mathrm{MOM}_{-1}$ impact the dependent variable in a complementary, mutually reinforcing manner. Since the Federal Reserve Bank can exert considerable influence on the slope of the yield curve by setting the short-term rates at which it provides liquidity to commercial banks, this finding has an important monetary policy implication: Monetary policy actions that have the primary objective of keeping inflation inside (or, at least, near) a pre-defined target range may have the unintended side effect of influencing the likely direction of future stock market returns or even abetting temporarily self-sustaining upward or downward trends in equity market prices. For the time being, it is an open question whether, and to what extent, such partially policy-induced trends and their eventual reversal (due to exogenous economic shocks and/or changes in the course of monetary policy) can have detrimental side effects on the stability of the financial sector or the economy as a whole. However, if they do, central bankers may find themselves facing a dilemma between the goals of maintaining a stable price level on one hand, and avoiding any unfavourable interference with the price formation processes on equity markets on the other.

\section{Conclusions}

This paper has re-examined two largely familiar anomalies in the stock market, the yield curve and the momentum effect, using the nonparametric method of locally linear regression. While essentially confirming the existence of both of these phenomena, the outcome of our empirical analysis nevertheless indicates that the patterns according to which the two indicators under consideration relate to future stock index returns are both nonlinear and mutually interlinked. Hence, it should be evident that the greater flexibility offered by the nonparametric regression model applied here enables the detection and statistical characterisation of some features of the empirical relationship under investigation that would have been remained undiscovered under the assumptions of linearity and additivity on which simpler regression models are based.

At this stage, however, it might easily concluded that this paper actually raises more questions than it answers. One might, for instance, ask whether the observed empirical relationships are mere statistical artefacts that would cease to prevail if additional relevant explanatory variables were taken into account. Moreover, the possibility that not just the most recently observed levels of the explanatory variables, but also the variability of the underlying quantities in a given, past time window may impact the dependent variable is clearly worth considering. Also, the question may arise whether the explanatory variables in use only affect the conditional mean of the index returns under examination (on which the current paper focused), or whether their entire risk profile is systematically influenced by these quantities. The authors feel that all these questions, and probably many more, are valid and pose important challenges for future research.

\section{References}

Alessandrini, P. and B. Nelson, 2012. Simple banking: Profitability and the yield curve. Bank of England Working Paper No. 452.

Ang, A. and M. Piazzesi, 2003. A no-arbitrage vector autoregression of term structure dynamics with macroeconomic and latent variables. Journal of Monetary Economics, 50(4): 745-787. View at Google Scholar | View at Publisher

Asness, C.S., J.M. Liew and R.L. Stevens, 1996. Parallels between the cross-sectional predictability of stock returns and country returns. Working Paper, Goldman Sachs Asset Management.

Basu, S., 1977. Investment performance of common stocks in relation to their price-earnings ratio: A test of the efficient market hypothesis. Journal of Finance, 32(2): 663-682. View at Google Scholar | View at Publisher

Boudoukh, J., M. Richardson and R.F. Whitelaw, 1997. Nonlinearities in the relation between the equity risk premium and the term structure. Management Science, 43(3): 371-385. View at Google Scholar | View at Publisher

Campbell, J.Y., 1987. Stock returns and the term structure. Journal of Financial Economics, 18(2): 373-399. View at Google Scholar $\mid$ View at Publisher

Campbell, J.Y. and J. Ammer, 1993. What moves the stock and bond market? A variance decomposition for long-term asset returns. Journal of Finance, 48(1): 3-37. View at Google Scholar | View at Publisher

Chan, K., H. Allaudeen and W. Tong, 2000. Profitability of momentum strategies in the international equity markets. Journal of Financial and Quantitative Analysis, 35(2): 153-172. View at Google Scholar | View at Publisher

Chen, N., R. Roll and S.A. Ross, 1986. Economic forces and the stock market. Journal of Business, 59: 383-403. View at Google Scholar

Chui, A.C.W., S. Titman and K.C.J. Wei, 2003. Momentum, legal system, and ownership structure: An analysis of Asian stock markets. Working Paper, University of Texas at Austin.

Diebold, F.X., G.D. Rudebusch and B. Aruoba, 2006. The macroeconomy and the yield Curve: A dynamic latent factor approach. Journal of Econometrics, 131(1-2): 309-338. View at Google Scholar | View at Publisher

Efron, B., 1979. Bootstrap methods: Another look at the jackknife. Annals of Statistics, 7(1): 1-26. View at Google Scholar |View at Publisher

Estrella, A. and G. Hardouvelis, 1991. The term structure as a predictor of real economic activity. Journal of Finance, 46(2): 555-576. View at Google Scholar | View at Publisher

Estrella, A. and F.S. Mishkin, 1996. The yield curve as a predictor of U.S. Recessions. Current Issues in Economics and Finance, 2(7): 1-6.

Estrella, A. and F.S. Mishkin, 1998. Predicting U.S. Recessions: Financial variables as leading indicators. Review of Economics and Statistics, 80(1): 45-61. View at Google Scholar | View at Publisher

Fama, E.F., 1970. Efficient capital markets: A review of empirical work. Journal of Finance, 25 (2): 383-41 7. View at Google Scholar | View at Publisher

Fama, E.F. and K.R. French, 1989. Business conditions and expected returns on stocks and bonds. Journal of Financial Economics, 25(1): 2349. View at Google Scholar | View at Publisher

Gilli, M. and E. Schumann, 2010. Robust regression with optimisation heuristics. In A. Brabazon, M. O’Neill, and D.Maringer (Editors. Natural computing in computational finance. Berlin: Springer, 3.

Gilli, M. and P. Winker, 2009. Heuristic optimization methods in econometrics. In: D. A. Belsley and E. Kontoghiorghes (Editors), Handbook of computational econometrics. Hoboken, NJ: Wiley. 
Gultekin, M.N. and N.B. Gultekin, 1983. Stock market seasonality: International evidence. Journal of Financial Economics, $12(4)$ : 469-481. View at Google Scholar

Hamilton, J.D., 1989. A new approach to the economic analysis of nonstationary time series and the business cycle. Econometrica, 57(2): $357-$ 384. View at Google Scholar | View at Publisher

Härdle, W., 1990. Applied nonparametric regression. Cambridge: University Press.

Hastie, T. and R. Tibshirani, 1993. Varying-coefficient models. Journal of the Royal Statistical Society, Series B, 55: 757-796. View at Google Scholar

Hong, H. and J.C. Stein, 1999. A unified theory of underreaction, momentum trading and overreaction in asset markets. Journal of Finance, 54(6): 2 143-2 184. View at Google Scholar | View at Publisher

Jegadeesh, N. and S. Titman, 1993. Returns to buying winners and selling losers: Implications for stock market efficiency. Journal of Finance, 48(1): 65-91. View at Google Scholar | View at Publisher

Jegadeesh, N. and S. Titman, 2001. Profitability of momentum strategies: An evaluation of alternative explanations. Journal of Finance, 56(2): 699-720. View at Google Scholar | View at Publisher

Li, Q. and J. Racine, 2007. Nonparametric econometrics: Theory and practice. Princeton, NJ: University Press.

Racine, J., 2008. Nonparametric econometrics - a primer. Foundations and Trends in Econometrics, 3(1): 1-88. View at Google Scholar $\mid$ View at Publisher

Resnick, B.G. and G.L. Shoesmith, 2002. Using the yield curve to time the stock market. Financial Analysts Journal, 58(3): 82-90. View at Google Scholar Richards, A.J., 1997. Winner-loser reversals in national stock market indices: Can they be explained? Journal of Finance, 52(5): $2129-2144$.
View at Google Scholar | View at Publisher

Rosenberg, B., K. Reid and R. Lanstein, 1985. Persuasive evidence of market inefficiency. Journal of Portfolio Management, 11(3): 9-16. View at Google Scholar | View at Publisher

Rouwenhorst, K.G., 1998. International momentum strategies. Journal of Finance, 53(1): 267-284. View at Google Scholar

Rouwenhorst, K.G., 1999. Local return factors and turnover in emerging stock markets. Journal of Finance, 54(4): 1439-1464. View at Google Scholar | View at Publisher

Schwert, W., 1990. Stock returns and real activity: A century of evidence. Journal of Finance, 45(4): 1237-1257. View at Google Scholar | View at Publisher

Shiller, R., 2005. Irrational exuberance. Princeton: University Press.

Siegel, J.J., 1998. Stocks for the long run. New York: McGraw Hill.

Smets, F. and K. Tsatsaronis, 1997. Why does the yield curve predict economic activity? Bank for international settlements. Working Paper No. 49, Basel.

Stock, J.H. and M.W. Watson, 2003. Forecasting output and inflation: The role of asset prices. Journal of Economic Literature, 41(3): 788829. View at Google Scholar | View at Publisher

Storn, R.N. and K.V. Price, 1997. Differential evolution - a simple and efficient heuristic for global optimization over continuous spaces. Journal of Global Optimization, 1 1(4): 341-359. View at Google Scholar

Tong, H., 1983. Threshold models in non-linear time series analysis. New York: Springer.

Tse, Y., 2015. Momentum strategies with stock index exchange-traded funds. North American Journal of Economics and Finance, 33: 134148. View at Google Scholar | View at Publisher 